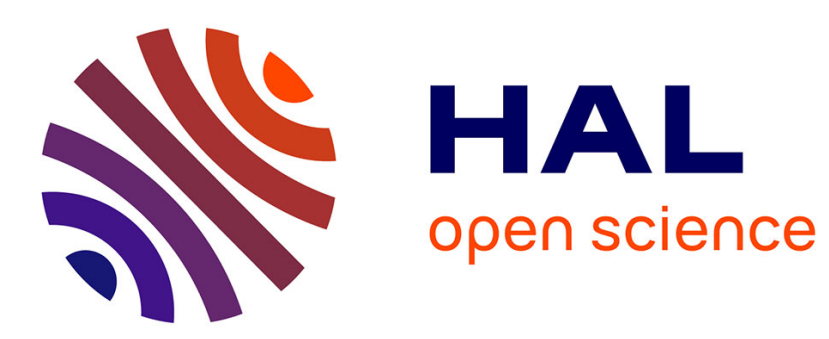

\title{
Single-crystal silicon nanoparticles: An instability to check their synthesis
}

Marjorie Cavarroc, Maxime Mikikian, Gaëlle Perrier, Laifa Boufendi

\section{To cite this version:}

Marjorie Cavarroc, Maxime Mikikian, Gaëlle Perrier, Laifa Boufendi. Single-crystal silicon nanoparticles: An instability to check their synthesis. Applied Physics Letters, 2006, 89, pp.013107. 10.1063/1.2219395 . hal-00097674

\section{HAL Id: hal-00097674 \\ https://hal.science/hal-00097674}

Submitted on 23 Nov 2009

HAL is a multi-disciplinary open access archive for the deposit and dissemination of scientific research documents, whether they are published or not. The documents may come from teaching and research institutions in France or abroad, or from public or private research centers.
L'archive ouverte pluridisciplinaire HAL, est destinée au dépôt et à la diffusion de documents scientifiques de niveau recherche, publiés ou non, émanant des établissements d'enseignement et de recherche français ou étrangers, des laboratoires publics ou privés. 


\title{
Single-crystal silicon nanoparticles: An instability to check their synthesis
}

\author{
M. Cavarroc, ${ }^{*}$ M. Mikikian, G. Perrier, and L. Boufendi \\ GREMI-Polytech'Orléans, 14, Rue d'Issoudun, BP 6744, 45067 Orléans cedex 2, France
}

\begin{abstract}
An instability occuring in electrical signals of the discharge is used as a mark to detect the end of the single-crystal silicon nanoparticle formation in $\mathrm{Ar} / \mathrm{SiH}_{4} \mathrm{rf}$ plasmas. Scanning electron microscopy and atomic force microscopy studies of depositions show that the exact beginning of the coalescence phase corresponds to the onset of the instability. At the end of the instability, no singlecrystal nanoparticles are remaining in the gas phase. These results based on a non-perturbative method allow to control depositions of single-crystal silicon nanoparticles of a well-defined size distribution with the highest density available during dust particle growth.
\end{abstract}

PACS numbers: 52.27.Lw, 52.35.-g, 52.70.-m

Dusty plasmas generated in radiofrequency (rf) discharges have been widely studied in the past few years. The range of interest spreads over industrial [1] as well as astrophysical concerns [2]. An active research has been induced by contamination phenomena in industrial plasma reactors. However, new applications of dust production have emerged. It can be used to produce analog aerosols of planet atmospheres like Titan [2]. The singlecrystal nanoparticles obtained by this way can be incorporated in thin film layers in order to improve their mechanical and/or optoelectronical properties [3], or used for single electron device fabrication [4]. Many theoretical $[5,6]$ and experimental $[7,8]$ studies have dealt with the detection and dynamics of particles in silane based plasmas. Presently, many studies are being carried out on the production of silicon nanoparticles generated in plasma processes [9].

In previous experimental and theoretical works $[7,10$, 11 , the way particles grow has been brougth to the fore. The dust particle formation in $\mathrm{Ar}-\mathrm{SiH}_{4}$ low pressure rf plasmas has been shown to be a four step process occuring in the gas phase: nanocrystal growth $(2-3 \mathrm{~nm}$ in diameter) from molecular species, accumulation phase, coalescence, and growth by deposition of the plasma species on the particle surface. Particle growth in the discharge leads to strong modifications of the plasma characteristics. Indeed dust grains affect many of the physical properties of the plasma (electron density, temperature, electric field, impedance, ...). The modification of the plasma impedance due to the particle formation and growth led us to use a diagnostic based on the time evolution of the amplitude of the third harmonic of the discharge current $(3 \mathrm{H})$ and the amplitude of the self-bias voltage $\left(\mathrm{V}_{d c}\right)[11]$. This electrical diagnostic has been developed in the GREMI laboratory. The current and voltage probes are inserted between the matchbox and the powered electrode. The curves are visualized on a LeCroy scope LT364L (500 MHz bandwidth and $1 \mathrm{GS} / \mathrm{s}$ ) and the results are recorded via a computer. This diagnostic has been shown to be able to follow the particle formation and growth in different chemistries such as silane and methane based ones [12]. Thus, in a pure argon plasma, the amplitude of $3 \mathrm{H}$ and $\mathrm{V}_{d c}$ remains constant in time. When silane is added to the the mixture, i.e. in a dust forming plasma, $\mathrm{V}_{d c}$ and $3 \mathrm{H}$ show a time evolution due to the formation and growth of dusts in the discharge.

\footnotetext{
*Electronic address: marjorie.cavarroc@univ-orleans.fr
}

The main formation steps (accumulation phase, coalescence and growth by surface deposition) can be clearly identify thanks to this electrical diagnostic (fig. 1). Even though, some uncertainties are remaining concerning the exact transition from one step to another. As can be seen in figure 1 insert, an instability occurs in between accumulation and coalescence phase [13].

Until now it was still quite difficult to exactely define when the coalescence starts. The end of the accumulation phase is the most interesting point for nanocrystal deposition. In a previous study performed in our group in the same experimental conditions, nanocrystals have been shown to be single-crystal silicon nanoparticles of 2-3 nm in the FCC phase[14] and the critical density (i.e. the greater density of nanocrystals in the discharge) is reached just at the end of this phase. A precise control of the nanocrystal phase is very important for all industrial applications in nanotechnologies in which a well known nanocrystal size and density are required [15]. The aim of the present work is to determine the point on electrical signals corresponding to the exact end of the accumulation phase (i.e. to the exact beginning of the coalescence phase).

The experimental set up has already been described in details in a previous paper [8]. The rf discharge is produced in a grounded cylindrical plasma box $(13 \mathrm{~cm}$ inner diameter and $3.3 \mathrm{~cm}$ for inter-electrode distance). The whole system is enclosed in a vacuum chamber. The upper electrode (driven electrode) is a shower-head one in order to ensure a homogeneous gas distribution at the entrance of the plasma zone. This electrode is connected to a $13.56 \mathrm{MHz}$ rf generator through a match box including a blocking capacitor. The power can be varied from 0 up to 20 Watts. The experimental conditions are the following: $12 \mathrm{~Pa}$ total pressure, $20 \mathrm{sccm}$ of argon flow

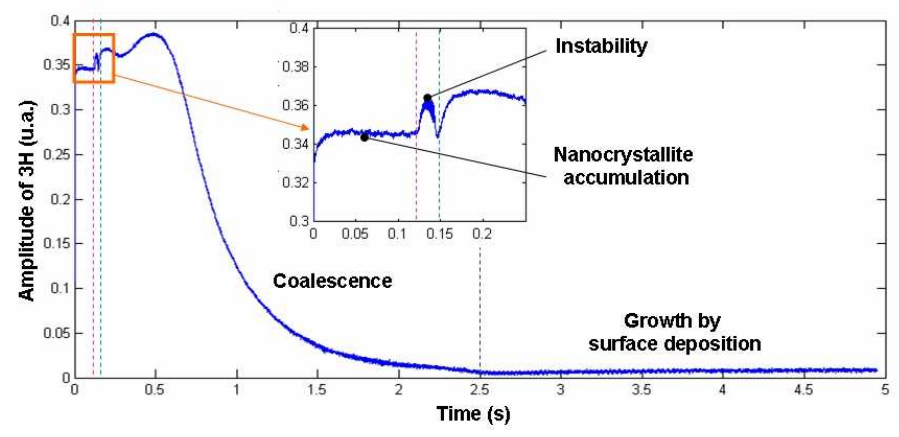

FIG. 1: (Color online) Time-evolution of the amplitude of the discharge current $3^{\text {rd }}$ harmonic in a dust forming plasma. 

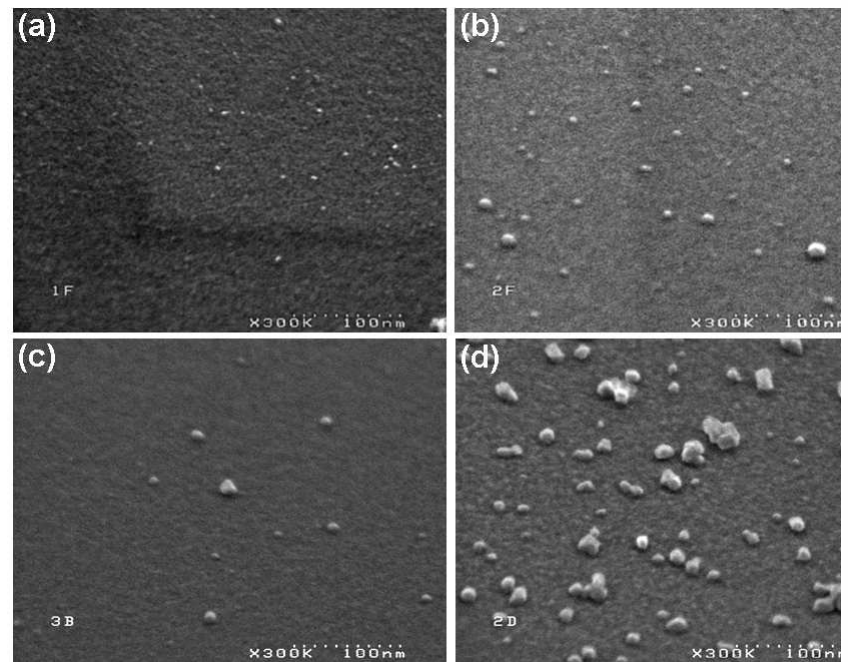

FIG. 2: SEM images of the samples deposited (a) just before (b) at the beginning of (c) during (d) after the instability.

rate, $1.2 \mathrm{sccm}$ of silane flow rate, 10 Watts of injected power, at room temperature.

In this work, depositions of dust particles at different instants have been performed. We used the instability occuring in the electrical signals as a mark. This instability has been studied in details in previous work [13]. We realized three different types of samples : a first one just before, a second one during, and a last one after the instability. Structural morphology of the formed dust particles is qualitatively analyzed from topographical observations of the samples by means of atomic force microscopy (AFM) operating in the tapping mode and scanning electron microscopy (SEM).The SEM images obtained are shown in figure 2 .

Just before the instability (figure 2(a)), there are only single nanocrystals (around 2-3 nm) on the substrate. At the beginning and in the middle of the instability (figure 2(b) and (c)), two populations can be distinguished: there are both nanocrystals and small polycrystalline aggregates. At the end of the instability (figure 2(d)) deposited dust particles are mainly small polycrystalline aggregates. These results seem to place the beginning of the coalescence phase at the beginning of the instability. The AFM images obtained from the same samples are shown in figure 3 . They are all normalized to the same height size scale in order to make the comparison easier. In the nanocrystal case, the AFM tip size is of the same order as the nanocrystal size. We are confronted to convolution troubles in the $\mathrm{x}$ and $\mathrm{y}$ directions. The only dimension we can use is the height because this dimension is less concerned by convolution troubles. The results are quite similar to the ones obtained by SEM. Before the instability (figure 3(a)), there are only small nanocrystals around $2-3 \mathrm{~nm}$ in height. At the beginning and in the middle of the instability (figure 3(b) and (c)), two populations of dust particles are present, one around 2-3 nm and another one around 4-5 nm. After the instability (figure $3(\mathrm{~d})$ ), a single population is visible, around $10 \mathrm{~nm}$. Those results confirm the ones obtained by SEM.

The radius distribution of dust particles corresponding to the first sample (figure 4(a)) shows a single peak centered at $1.5 \mathrm{~nm}$ (corresponding to $3 \mathrm{~nm}$ in height).
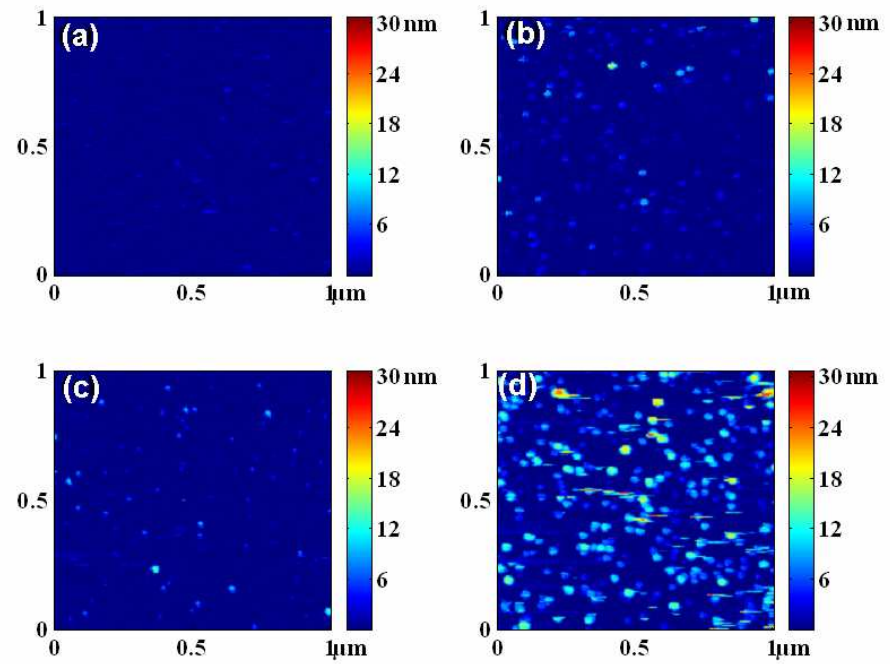

FIG. 3: (Color online)AFM images of the samples deposited (a) just before (b) at the beginning of (c) during (d) after the instability.

The same analysis performed on a sample deposited during the instability (figure 4(b)) shows two peaks located at different heights. The higher peak around $1.5 \mathrm{~nm}$ corresponds to the nanocrystals and the smaller one around $4 \mathrm{~nm}$ corresponds to the first coalesced polycrystalline nanoparticles. On the last sample (figure $4(\mathrm{c})$ ), a single peak appears around $5 \mathrm{~nm}$, corresponding to bigger coalesced polycrystalline nanoparticles. Those dust particle radius distributions confirm our qualitative topographical observation.

The third harmonic/self-bias based diagnostic does not need any optical access to the plasma. Once it is calibrated, this diagnostic can provide precise information concerning the dust particle nature in the discharge. We performed the calibration for the first phases of formation (formation and accumulation of nanocrystals and beginning of the coalescence) in a typical dust forming $\mathrm{Ar} / \mathrm{SiH}_{4}$ plasma generated in a rf
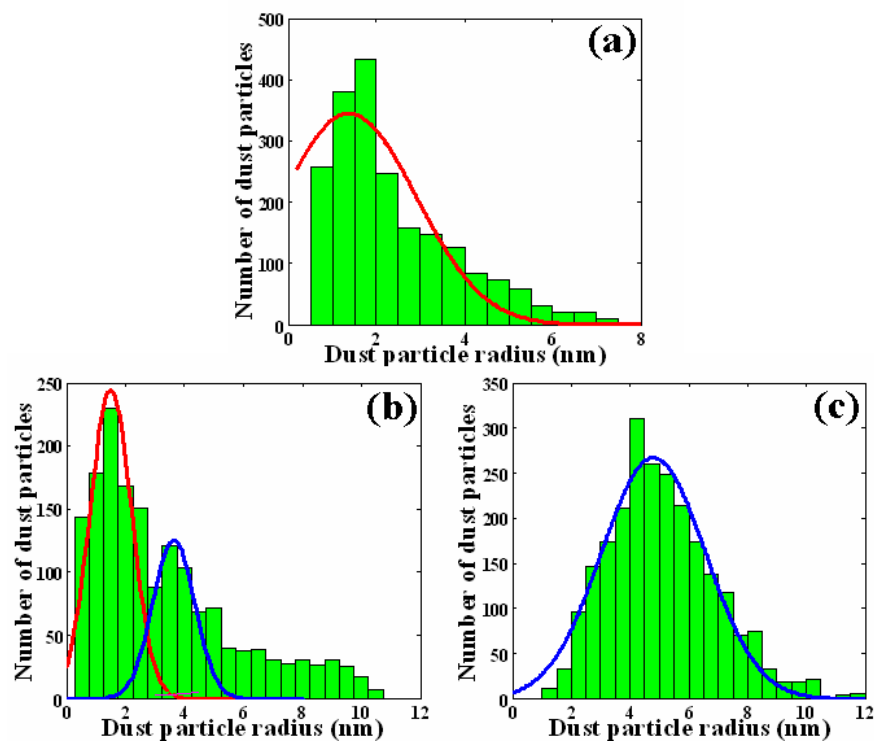

FIG. 4: (Color online) Radius distribution diagrams corresponding to a sample deposited (a)before (b) during (c) after the instability. 
discharge. Presently, we can conclude that before the instability, the dust particles are single-crystal silicon nanoparticles of $2-3 \mathrm{~nm}$ in diameter in the FCC phase [14]. Their shape appears to be spherical and their density increases during the accumulation phase until reaching the critical value estimated to $10^{11}$ to $10^{12}$ $\mathrm{cm}^{-3}$ at room temperature [11]. Thereby, just before the instability the single-crystal silicon nanoparticle density in the plasma is the highest that can be reached. During the instability, nanocrystals agglomerate together to form the first polycrystalline dust nanoparticles of 4-5 $\mathrm{nm}$. All the nanocrystals begin to agglomerate at least two by two. This is the early beginning of the coalescence phase and two populations can be distinguished. The first one corresponds to nanocrystals while the second one corresponds to first coalesced polycrystalline particles. At the end of the instability, no more single nanocrystals remain in the gas phase. Thus, the onset of the instability exactly corresponds to the beginning of the coalescence phase. This instability is certainly due to a charge effect of the nanoparticles becoming bigger and starting to attach more electrons. It can be related to attachment induced ionization instabilities observed in electronegative gases [13, 16, 17]. After the instability the dust nanoparticles are made of agglomerated nanocrystals. Their size increases from 5 $\mathrm{nm}$ at the beginning of the coalescence to about $45 \mathrm{~nm}$ at the end of the phase [1]. The dust particles are now polycrystalline and present a high specific surface (up to $115 \mathrm{~m}^{2} \cdot \mathrm{g}^{-1}[18]$ ) that can be of interest for applications in catalysis.

The authors would like to thank M. Dudemaine, S. Dozias, M. Vayer, T. Baron and K. Aissou for technical support.
[1] L. Boufendi and A. Bouchoule, Plasma Sources Sci. Technol. 11, p. A211, 2002

[2] G. Cernogora, C. Szopa, L. Boufendi, P. Coll, J.M. Bernard and C. Pintassilgo, AIP Conference Proceedings 799, 2005

[3] P. Roca i Cabarrocas, N. Chaabane, A.V. Kharchenko and S. Tchakarov, Plasma Phys. Control. Fusion 46,p. B235, 2004

[4] S. Tiwari, F. Rana, H. Hanafi, A. Hartstein and E. F. Crabb, Appl. Phys. Lett. 68, p. 1377, 1996

[5] L. Boufendi, A. Bouchoule and T. Hbid, J. Vac. Sci. Technol. A 14(2), p. 572, 1996

[6] J.P. Boeuf, Phys. Rev. A 46, 1992

[7] A.A. Fridman, L. Boufendi, T. Hbid, B.V. Potapkin and A. Bouchoule, J. Appl. Phys. 79, p.1303, 1995

[8] A. Bouchoule, A. Plain, L. Boufendi, J.Ph. Blondeau and C. Laure, J. Appl. Phys. 70, p. 1991, 1991

[9] A. Bapat, C. Anderson, C. R. Perrey, C. B. Carter, S. A. Campbell and U. Khortshagen, Plasma Phys. Control. Fusion 46, p. B97, 2004

[10] M. Shiratani, T. Fukuzawa and Y. Watanabe, Jpn. J.
Appl. Phys. 38, p. 4542, 1999

[11] L. Boufendi, J. Gaudin, S. Huet, G. Viera and M. Dudemaine, Appl. Phys. Lett. 79, p. 4301, 2001

[12] A. Mezeghrane, M. Jouanny, M. Cavarroc, M. Mikikian, O. Lamrous and L. Boufendi, Proceedings of the 31th EPS Conference on Plasma Physics, London, edited by P. Norrey and H. Hutchinson (European Physical Society) ECA-28G, 2004

[13] M. Cavarroc, M.C. Jouanny, K. Radouane, M. Mikikian and L. Boufendi, J. Appl. Phys. 99, 064301, 2006

[14] G. Viera, M. Mikikian, E. Bertran, P. Roca i Cabarrocas and L. Boufendi, J. Appl. Phys. 92, p. 4684, 2002

[15] K. Nishiguchi, X. Zhao and S. Oda, J. Appl. Phys. 92, p. 2748, 2002

[16] W.L. Nighan and W.J. Wiegand, Phys. Rev. A 10, p. 922, 1974

[17] A. Descoeudres, L. Sansonnens and Ch. Hollenstein, Plasma Sources Sci. Technol. 12, p. 152, 2003

[18] F. Vivet, A. Bouchoule and L. Boufendi, J. Appl. Phys. 83, p. 7474, 1998 